\title{
Human Herpesvirus 8 Positive
}

National Cancer Institute

\section{Source}

National Cancer Institute. Human Herpesvirus 8 Positive. NCI Thesaurus. Code C146672.

An indication that human herpesvirus 8 has been detected in a sample. 